\title{
High Frequency of Pfcrt-76T Allele in Plasmodium falciparum Isolates From Gabon and Ivory Coast After the Withdrawal of Chloroquine
}

\author{
Fréquence élevée de l'allèle Pfcrt-76T dans les isolats de Plasmodium falciparum provenant \\ du Gabon et de la Côte d'Ivoire après le retrait de la chloroquine
}

\author{
J.M. Ndong Ngomo - M. Amiah Ahou - W. Yavo - M. Karine Bouyou-Akotet · D.P. Mawili-Mboumba
}

Received: 10 August 2018; Accepted: 2 April 2019

(C) Société de pathologie exotique et Lavoisier SAS 2019

\begin{abstract}
The aim of this study was to assess the proportion of Pfcrt-76T mutant allele four years after the adoption of new malaria control guidelines in Gabon and Ivory Coast. Frequency of K76T mutation of Pfcrt gene was compared between Plasmodium falciparum isolates from Gabon and Ivory Coast. Samples were collected in 2008 in Gabon and in 2009 in Ivory Coast. In total, 151 isolates were selected and analysed by nested-PCR-RFLP for Pfcrt-76 allele identification: 63 in Abobo (Ivory Coast) and 78 in Oyem (Gabon). The proportion of Pfcrt-76T mutant allele was higher in Oyem $(70 \%)$ compared to Abobo $(46 \%)(\mathrm{p}=0.005)$. This allele was more frequently detected in patients less than 5 years old in Oyem (75\%) compared to Abobo (52\%) $(p<0.01)$. The present work showed different prevalence of $P f c r t-76 \mathrm{~T}$ allele between both sites probably due to a different drug pressure on $P$. falciparum strains circulating in these areas. Moreover, a decrease of the mutation frequency is observed compared to data obtained in 2005 . Therefore, a continuous monitoring of this allele and other drug resistance molecular markers is required in these countries.
\end{abstract}

Keywords Malaria - Plasmodium falciparum - Resistance · Chloroquine $\cdot$ Pfcrt gene $\cdot$ Ivory Coast · Gabon · SubSaharan Africa

\footnotetext{
J.M. Ndong Ngomo $(\bowtie) \cdot$ M. Karine Bouyou-Akotet

D.P. Mawili-Mboumba

Faculté de médecine, Département de parasitologie

et de mycologie, Université des sciences de la Santé, BP 4009, Libreville, Gabon

e-mail : 06etindong@gmail.com
}

M. Amiah Ahou $\cdot$ W. Yavo

Centre de recherche et de lutte contre le paludisme, Institut national de santé publique,

BPV 47, Abidjan, Côte d'Ivoire

J.M. Ndong Ngomo $\cdot$ M. Amiah Ahou $\cdot$ W. Yavo Laboratoire de génétique, UFR biosciences, Université Félix Houphouët-Boigny, BPV 34, Abidjan, Côte d'Ivoire
Résumé Le but de cette étude était d'évaluer la proportion de l'allèle mutant $P f c r t-76 \mathrm{~T}$ quatre ans après l'adoption de nouvelles stratégies de contrôle du paludisme au Gabon et en Côte d'Ivoire. La fréquence de la mutation K76T du gène $P f c r t$ a été comparée entre les isolats de P. falciparum du Gabon et de Côte d'Ivoire. Des échantillons ont été prélevés en 2008 au Gabon et en 2009 en Côte d'Ivoire. Au total, 151 isolats ont été sélectionnés et analysés par PCRnichée-RFLP pour l'identification de l'allèle Pfcrt-76: 63 à Abobo (Côte d'Ivoire) et 78 à Oyem (Gabon). La proportion de l'allèle mutant $P f c r t-76 \mathrm{~T}$ était plus élevée à Oyem $(70 \%)$ comparée à Abobo $(46 \%)(p=0,005)$. Cet allèle était plus fréquemment détecté chez les patients de moins de 5 ans à Oyem $(75 \%)$ comparé à Abobo $(52 \%)(\mathrm{p}<0,01)$. Le présent travail a montré une prévalence différente de l'allèle Pfcrt-76T entre les deux sites, probablement en raison d'une pression médicamenteuse différente sur les souches de $P$. falciparum circulant dans ces zones. Une diminution de la fréquence de cette mutation est observée par rapport aux résultats de 2005. Par conséquent, un suivi continu de cet allèle et d'autres marqueurs moléculaires de la résistance aux antipaludiques est recommandé dans ces pays.

Mots clés Paludisme Plasmodium falciparum ' Résistance . Chloroquine · Gène Pfcrt . Côte d'Ivoire · Gabon · Afrique intertropicale

\section{Background}

Chloroquine (CQ) was a highly effective antimalarial drug during decades in malaria endemic areas. It has conducted to a reduction of malaria morbidity [9]. However, the emergence of CQ resistant Plasmodium falciparum (P. falciparum) strains, in the 1950's in Southeast Asia and Latina America and in the 1980's in Africa, conducted to the abandonment of 
this drug. CQ therapeutic failures have been attributed to parasites carrying mutant forms of Pfcrt gene [8].

The substitution of lysine $(\mathrm{K})$ by tyrosine $(\mathrm{T})$ at codon 76 of the PfCRT protein was linked to P. falciparum resistance to CQ [2]. This mutation was found in all samples collected in 2005 in Ivory Coast and in those collected between 1995 and 2002 in Gabon [1,3]. In the beginning of 2000's most of malaria endemic countries have replaced CQ by artemisinin-based combination therapies (ACTs) [9]. Since 2005, in Ivory Coast and Gabon, artesunateamodiaquine combination was used as first-line treatment and artemether-lumefantrine as second line for the treatment of uncomplicated malaria. Nine years after, both combinations are used as first-line treatment, artesunate-mefloquine or dihydroartemisin-phosphate piperaquine being the second line treatment. Many surveys reported that withdrawal of CQ is followed by a significant decrease of Pfcrt-76T frequency [5]. The aim of this study was to compare Pfcrt-76T allele distribution in $P$. falciparum isolates collected in Abobo (Ivory Coast) and Oyem (Gabon) after withdrawal of CQ and the deployment of ACTs in these countries.

\section{Material and Methods}

Cross-sectional studies were conducted from September 2008 to February 2009 in General Hospital of Abobo and from February 2008 to January 2009 in the Regional Hospital of Oyem (RHO) in the north of Gabon.

Malaria transmission is perennial in both sites. In Oyem and in Abobo, malaria prevalence was $39 \%$ and $61.9 \%$, respectively at the time of samples collection. RHO is one of the five sentinel sites selected for malaria survey by the Malaria National Control Programme (MNCP) in Gabon. The General Hospital of Abobo is a study site selected by the team of Malaria Research and Control Center of the National Institute of Health of Abidjan, to assess the prevalence of malaria among febrile patients.

Peripheral blood samples were collected from febrile children aged less than 11 years in Oyem and from patients aged less than 54 years in Abobo. The oral consent of adults patients and of the parents or legal guardians of children was obtained.

Age, sex, temperature, and others demographic data were recorded.

Blood samples were collected for malaria parasite diagnosis based on microscopic examination of Giemsa-stained thick film in both sites. Moreover, approximately, $50 \mu \mathrm{L}$ of blood were spotted onto filter papers (Watman ${ }^{\mathrm{TM}}$ ). Each was dried and stored with two desiccants in plastic bags at room temperature $\left(20^{\circ} \mathrm{C}\right)$ until DNA extraction. Before molecular analysis, $10 \%$ of $P$. falciparum infected samples were randomly selected. DNA was extracted from dried blood spot
(DBS) using Chelex 100 at 5\% according to manufacturer's instructions (Bio-Rad, Laboratories, Hercules, CA). NestedPolymerase Chain Reaction Restriction Fragment Length Polymerase (Nested PCR-RFLP) was used for mutant ( $P f c r t$ -76T) and wild-type (Pfcrt-76K) allele's detection [8]. The amplicons and digested products were revealed by electrophoresis on $2 \%$ agarose gel. The transilluminator (UV) was used for the visualization of fragments.

Molecular analysis performed on samples collected in 2008 in Gabon is described elsewhere [7]. Similar methods have been used for all selected samples.

Data were analysed using Epi Info ${ }^{\mathrm{TM}} 7$. All variables were compared using Chi 2 or Fisher test exact to compare the proportion. P-value $<0.05$ was considered statistically significant. Mixed infection concerned the isolates carrying wild type and mutant type alleles at codon 76 .

\section{Ethical Consideration}

The study performed under the direction of Ministry of Health of Ivory Coast was approved by the National Ethics Committee. In Gabon, the Department of ParasitologyMycology and Tropical Medicine of the Faculty of Medicine of Libreville is committed by the Gabonese Ministry of Health represented by MNCP, to perform the evaluation of malaria prevalence and antimalarial drug resistance monitoring throughout the country.

\section{Results}

A total of 689 patients from Oyem and 634 patients from Abobo were screened. Among these patients, 63 have been selected in Abobo and 78 in Oyem. The median age of screened patients from Oyem is 2 [1-4] years old and that of selected patients 2 [1.8-4] years old were comparable $(\mathrm{p}=0.1)$. In this site, the frequency of female patients was also similar between screened patients and selected ones: $46.4 \%(320 / 689)$ vs $54 \%(42 / 78)$ respectively $(\mathrm{p}=0.2)$.

In Abobo, the median age of screened patients, 6 [5.4-7] years old, was comparable to that of selected patients (6 [5-7 ] years old $(\mathrm{p}=0.2)$. The frequency of female patients was lower in the group of screened patients: $24.7 \%(157 / 634)$ vs $51 \%(27 / 63)$ in selected group $(\mathrm{p}=0.003)$.

Among selected patients $(\mathrm{n}=141)$ female represented $48.9 \%(n=69 / 141)$ of the patients.

Patients aged more than 10 years old $(n=15)$ were all from Abobo. The proportion of children less than 5 years old was $61.7 \%(\mathrm{n}=87 / 141)$. They were $76.9 \%(\mathrm{n}=60 / 78)$ in Oyem and $42.8 \%(\mathrm{n}=27 / 63)$ in Abobo $(\mathrm{p}<0.01)$. Among patients, $27,7 \%(\mathrm{n}=39 / 141)$ were older children ([5-10] years). They 
were $33.3 \%(\mathrm{n}=21 / 63)$ in Abobo and $23.1 \%(\mathrm{n}=18 / 78)$ in Oyem $(p=0.2)$.

The median parasite density was 19280 [19000-20400] p/ $\mu \mathrm{L}$; and was 1.6 fold higher in patients from Oyem: 21618 [21000-22360] $\mathrm{p} / \mu \mathrm{L}$ vs 13400 [12360-16000] $\mathrm{p} / \mu \mathrm{L}$ in Abobo.

Overall, Pfcrt-76T mutant allele was detected in 59.5\% $(n=84 / 141)$ of the isolates (Table I). This proportion was significantly higher in Oyem compared to Abobo: $70 \%$ $(\mathrm{n}=55 / 78)$ vs 4\% $(\mathrm{n}=30 / 63)$, respectively $(p<0.01)$ (Table I). None isolate carried a mixed infection in Oyem while three were found in Abobo (Table 1). The median age of patients infected by mutant parasites was 3 [2-4] years comparable to that of patients harbouring wild type parasites: 4 [3-5] years. The proportion of K76T mutation was comparable between the patients less than 5 years old ( $63 \%$; $\mathrm{n}=55 / 87)$ and patients aged between 5 and 10 years $(54 \%$; $n=21 / 39)(p=0.4)$. In Oyem, the frequency of mutant allele was significantly different according to age being the highest among the youngest patients: $75 \%$ vs $55 \%(p=0.02)$. In Abobo, the proportion of this allele was similar between both groups: $52 \%$ vs 52\% ( $p=0.6$ ) (Table 2). Comparing patients less than five years old from both sites, those infected by mutant parasites ( $P f c r t-76 \mathrm{~T}$ allele) were less frequent in Abobo $(52 \% ; n=14 / 27)$ than those from Oyem $(75 \% ; n=45 / 60)(p<0.01)$ (Table II). In contrast, the propor- tion of mutant isolates was comparable in patients aged between 5 and 10 years from Oyem $(n=10 / 18)$ and from Abobo $(\mathrm{n}=11 / 21)(p=0.5)$ (Table II). Among adult patients in Abobo; 8/15carried mutant alleles and one patient harboured a mixed infection.

\section{Discussion}

Monitoring the occurrence of malaria parasite resistance to antimalarial drugs and its spread is essential in all malariaendemic areas notably after introduction of new antimalarial drugs. For this purpose, molecular markers are good tools. Prior to the change of the national policy of malaria treatment, the prevalence of the mutant Pfcrt allele $76 \mathrm{~T}$ was around $97 \%$ in the centre of Gabon and $100 \%$ at Bonoua, at $59 \mathrm{~km}$ from Abobo in Ivory Coast in 2005 [1,3]. In the present work, lower prevalence of mutant alleles ( $P f c r t-76 \mathrm{~T})$ is found in Abobo (48\%) and in Oyem Gabon (70\%) 3 to 4 years after CQ withdrawal. These data corroborate with those reported in Congo (52.1\%) and Sierra Leone (54.0\%) where a decreasing frequency of mutant allele was observed [10]. Nevertheless, the decline of Pfcrt-76T allele frequency was different according to each endemic area. This decline is lower in Abobo than in Oyem suggesting a different antimalarial drug pressure between sites. It has also been reported

Table 1 Comparison of prevalence of the mutation K76T of Pfcrt gene at Oyem and Abobo according to sites / Comparaison de la prévalence de la mutation K76T du gène Pfcrt à Oyem et Abobo en fonction des sites

\begin{tabular}{|llllll}
\hline Pfcrt K76T & $\begin{array}{l}\text { Oyem-2008 } \\
\mathbf{n = 7 8}\end{array}$ & $\begin{array}{l}\text { Abobo-2009 } \\
\mathbf{n = 6 3}\end{array}$ & $\boldsymbol{P}$ & OR (95\% CI) & $\begin{array}{l}\text { All } \\
\mathbf{N = 1 4 1}\end{array}$ \\
\hline Mutant single 76T, n (\%) & $55(70.5)$ & $27(42.8)$ & $<0.01$ & $3.40(1.6-6.8)$ & $57.4(81)$ \\
Wild single 76K, n (\%) & $23(29.5)$ & $33(52.3)$ & $<0.01$ & $0.38(0.1-0.7)$ & $39.7(56)$ \\
MI** 76K/T, n (\%) & $0(0.0)$ & $3(4.7)$ & - & - & $2.1(3)$ \\
Total mutant 76T, n (\%) & $55(70.5)$ & $30(47.6)$ & 0.005 & $2.8(1.3-5.6)$ & $59.5(84)$ \\
Total wild 76K, n (\%) & $23(29.5)$ & $36(57.1)$ & $<0.01$ & $0.3(0.1-0.6)$ & $41.8(59)$
\end{tabular}

** MI (mixed infection): isolate carrier mutant $76 \mathrm{~T}$ and wild $76 \mathrm{~K}$ allele's type / IM (Infection Mixte) : isolat porteur d'allèle mutant 76 T et d'allèle sauvage $76 \mathrm{~K}$

Table 2 Proportion of Pfcrt-76T and Pfcrt-76K alleles according to age and sites / Proportion des alleles Pfcrt-76T et Pfcrt-76K en fonction de l'âge et des sites

\begin{tabular}{|lllllll|}
\hline & Mutant & Wild & $\boldsymbol{p}$ & OR (95\% CI) \\
\hline Median age (years) & $3[2.5-3.5]$ & $4[3-5]$ & & - & $3[1-28]$ \\
Abobo-2009 & $<5$ years, \% (n) & $51.8(14 / 27)$ & $62.9(17 / 27)$ & 0.5 & $0.6(0.2-1.8)$ & $7.4(2 / 27)$ \\
& $\geq 5$ years, \% (n)* & $52.3(11 / 21)$ & $47.6(10 / 21)$ & 0.5 & $1.2(0.3-4.0)$ & 0.0 \\
Oyem-2008 & $<5$ years, \% (n) & $75.0(45 / 60)$ & $25.0(15 / 60)$ & $<0.001$ & $9.0(3.9-20.5)$ & 0.0 \\
& $\geq 5$ years, \% (n) & $55.5(10 / 18)$ & $44.4(8 / 18)$ & 0.1 & $1.5(0.4-5.8)$ & 0.0 \\
\hline \multirow{2}{*}{ *This group concerned only the children aged from 5 to 10 years / Ce groupe concernait seulement les enfants âgés de 5 à 10 ans } \\
\hline
\end{tabular}


that CQ resistance has a fitness cost in terms of parasite reproduction; thus sensitive parasites have a survival advantage in the absence of drug pressure [4].

Otherwise, antimalarial drug for self-medication that constitutes a key component of antimalarial drug resistance development and spread, is frequent in Oyem and may explain the slow decrease of mutant allele frequency in this area [10]. The prevalence of self-medication was near $30 \%$ in Oyem and lower in Abobo, Ivory Coast, $11.1 \%$ [6]. Moreover, although CQ has been withdrawn, other 4-aminoquinoleines such as amodiaquine are still used in combination with artemisinin derivatives. ACTs and other antimalarial drugs are frequently sold in pharmacies for self-medication use.

According to age, a predominance of $P f c r t-76 \mathrm{~T}$ allele was observed in isolates from patients less than 5 years old in urban $(100 \%)$ and rural areas $(86.2 \%)$ in 2005 in Ivory Coast [1]. In the present study, the prevalence of this allele (Pfcrt-76T) is still high in this group, notably in Oyem. $P f$ crt-76T allele was detected in a study carried out in Angola in more than $80 \%$ of asymptomatic adults [2]. In the present study, this allele was found in $54 \%$ of adults.

All codons of $P f$ crt gene related to antimalarial drug resistance have not been analysed in this study and this may constitute the main limit of this investigation. Therefore, the detection of additional mutations in this gene may be of importance in isolates from Gabon and Ivory Coast [8].

\section{Conclusion}

This study shows a different distribution of $P f c r t-76 \mathrm{~T}$ allele between Abobo (Ivory Coast) and Oyem (Gabon) after withdrawal of chloroquine. Moreover, a relation between the prevalence of the K76T mutation and the age was found in Oyem. The high frequency of this mutation underlines the importance of monitoring $P$. falciparum strains genetic profile to protect the antimalarial molecule partners used with artemisinin.

Acknowledgements We are grateful to the patients who participated to the study and the staff of both Departments of Parasitology and Mycology of Libreville and Abidjan.
Conflict of interest : The authors do not have any conflict of interest to declare

\section{References}

1. Ako BA, Offianan AT, Johansson M, et al (2012) Molecular analysis of markers associated with chloroquine and sulfadoxine/pyrimethamine resistance in Plasmodium falciparum malaria parasites from southeastern Côte-d'Ivoire by the time of Artemisinin-based Combination Therapy adoption in 2005. Infect Drug Resist 5:11320. doi: 10.2147/IDR.S31409. Epub 2012 Aug 1.

2. Foumane Ngane V, Allico Djaman J, Culeux C, et al (2015) Molecular epidemiology of drug-resistant Plasmodium falciparum in Benguela province, Angola. Malar J 14:113. doi: 10.1186/s12936-015-0634-2.

3. Frank M, Lehners N, Mayengue PI, et al (2011) A thirteen-year analysis of Plasmodium falciparum populations reveals high conservation of the mutant pfcrt haplotype despite the withdrawal of chloroquine from national treatment guidelines in Gabon. Malar J 10:304. doi: 10.1186/1475-2875-10-304

4. Kublin JG, Cortese JF, Njunju EM, et al (2003) Reemergence of chloroquine-sensitive Plasmodium falciparum malaria after cessation of chloroquine use in Malawi. J Infect Dis 187(12):18705. Epub 2003 May 21.

5. Maghendji-Nzondo S, Kouna LC, Mourembou G, et al (2016) Malaria in urban, semi-urban and rural areas of southern of Gabon: comparison of the Pfmdr 1 and Pfcrt genotypes from symptomatic children. Malar J 15(1):420. doi: 10.1186/s12936-016-1469-1.

6. Mawili-Mboumba DP, Bouyou-Akotet MK, Kombila M (2011). Usage des antipaludiques en automédication pour le traitement de la fièvre chez les enfants au Gabon. Santé 21(3):127-31. doi: 10.1684/san.2011.0267

7. Mawili-Mboumba DP, Ndong Ngomo JM, Maboko F, et al (2014) Pfcrt 76T and Pfmdr1 86Y allele frequency in Plasmodium falciparum isolates and use of self-medication in a rural area of Gabon. Trans R Soc Trop Med Hyg 108(11):729-34. doi: 10.1093/trstmh/tru147. Epub 2014 Sep 23

8. Warhurst DC (2001) A molecular marker for chloroquineresistant falciparum malaria. New Engl J Med 344(4):257-63

9. WHO (2005) World malaria report 2005 - World Health Organization, $316 \mathrm{p}$

10. Zhou RM, Zhang HW, Yang CY, et al (2016) Molecular mutation profile of pfert in Plasmodium falciparum isolates imported from Africa in Henan province. Malar J 15(1):265. doi: 10.1186/s12936-016-1306-6 